\title{
Modelo experimental para estudo de Anatomia Humana em cadáveres
}

\author{
Experimental model for human anatomy study in corpses \\ Rafael de Azevedo Silva', Marilia Silva da Luz', Hícaro Donato Granhen'1, Eduardo Silva Furtado de Mendonça², \\ Mauro Ricardo Souza da Luz ${ }^{3}$, Franklin Coelho Nascimento ${ }^{4}$
}

Resumo Objetivo: O objetivo deste modelo experimental é utilizar o bisturi quente (ferro de solda adaptado) como recurso alternativo para a dissecação de estruturas anatômicas envoltas em tecido adiposo e encurtar o tempo nesse processo. Método: Para a confecção do Bisturi Quente, adaptou-se uma lâmina de bisturi na extremidade de um Ferro de Solda de 110V-70W. Resultados: Com o toque do Bisturi Quente, após ser ligado, ocorreu a liquefação do tecido adiposo que envolvia a estrutura anatômica e, além disso, realizou-se o processo de detalhamento da estrutura evidenciando suas características - feito que o trabalho com instrumentos cirúrgicos padrões não é possível de realizar. Conclusão: O modelo proposto proporcionou uma alternativa segura de dissecações de tecido adiposo, bem como reduziu o tempo gasto na tarefa quando comparado com o trabalho com instrumentais cirúrgicos padrões.

Descritores: medicina; educação médica; dissecação; anatomia.

Summary Objective: The objective of this experimental model is to the hot scalpel (adapted soldering iron) as an alternative resource for the dissection of anatomical structures enveloped in adipose tissue and shorten the time in this process. Method: For the preparation of the Hot Sprue, a end of a 110V-70W Welding Iron. Results: At the touch of the Hot Sprue, after being switched on, liquefaction of the tissue occurred adipose tissue that involved the anatomical structure and, in addition, the process of detailing the structure was evidenced its characteristics - made that working with standard surgical instruments is not possible to perform. Conclusion: The proposed model provided a safe alternative for dissecting adipose tissue, as well as reducing the time spent on the task when compared with working with standard surgical instruments.

Keywords: medicine; education, medical; dissection; anatomy. 


\section{Introdução}

Com a evolução tecnológica, o estudo da Anatomia Humana nas escolas médicas é trabalhado através da utilização de peças anatômicas de plástico e projeções de computadores sem a fidedignidade do corpo humano e a sensação palpável do toque em órgãos, tecidos e estruturas do corpo ${ }^{1-3}$.

Contudo, a dissecação de cadáveres ainda é a prática de maior valor de ensino, por se tratar de uma análise do corpo humano original que proporciona o estudo adequado de regiões e topografias que não a peça anatômica industrial não proporciona, além de gerar uma percepção tátil de espessura e sensibilidade de tecidos e órgãos ${ }^{3,4}$.

Para desenvolver o estudo da Anatomia Humana é necessário realizar o processo de Dissecação. Por conta de sua estrutura e composição do corpo, torna-se complicada e demorada a dissecação de alguns tipos de tecido sem lesar qualquer tipo de estrutura, como é o caso da dissecação de órgãos envoltos por tecido adiposo, dificultando a exposição mais bem detalhada das estruturas de interesse em um menor tempo e atrapalhando o objetivo pedagógico de aprendizado de anatomia ${ }^{5}$.

O objetivo deste protótipo é utilizar o bisturi quente (ferro de solda adaptado) como recurso alternativo para a dissecação de estruturas anatômicas envoltas em tecido adiposo e encurtar o tempo nesse processo.

\section{Método}

Para a realização do modelo experimental proposto foram necessários os seguintes materiais (Tabela 1): ferro de solda (110V-70W), lâminas (Figura 1) e chave de fenda.

Para a confecção do modelo experimental, seguiram-se as seguintes etapas:

1) Retirada da extremidade do ferro de solda (Figura 2): auxiliado por uma chave de fenda foi feita a retirada da extremidade do ferro de solda por meio através da remoção dos parafusos que fixavam;

2) Foi realizada a adaptação de uma lâmina na extremidade do ferro de solda (Figura 3);

3) Por fim, auxiliado por uma chave de fenda, recoloca-se os parafusos anteriormente retirados.

\section{Resultados}

Com o toque do Bisturi Quente, após ser ligado, ocorreu a liquefação do tecido adiposo que envolvia a estrutura anatômica, possibilitando o detalhamento da estrutura e evidenciando suas características - feito este que não seria possível de realizar com a utilização de instrumentos cirúrgicos comumente utilizados (tesoura e pinça).

O modelo experimental se mostrou prático em sua construção e, pela diminuição do tempo gasto na dissecação de estruturas, possibilita ser uma alternativa para o desenvolvimento pedagógico de estudo da Anatomia Humana

Tabela 1. Lista de materiais utilizados

Material
- Ferro de Solda (110V-70W)
- Lâminas de Bisturi
- Chave de Fenda

Fonte: Autores. Legenda: V (Volts) e W (Watt).

\section{Discussão}

Inúmeros trabalhos na literatura referenciam a necessidade do estudo da Anatomia Humana como a construção base de qualquer conhecimento que virá a ser adquirido durante a graduação e, para suprir essa necessidade, existe o atual desenvolvimento industrial no ramo dos modelos anatômicos que tendem a ser anatomicamente similares com o corpo humano.

Contudo, esses modelos são caracterizados pela baixa semelhança tátil, sensorial e topográfica em comparação com o que o cadáver pode proporcionar para o estudo da Anatomia. Somado a isso, o modelo industrial possui um alto valor para sua aquisição por ser confeccionado industrialmente, dificuldade que 


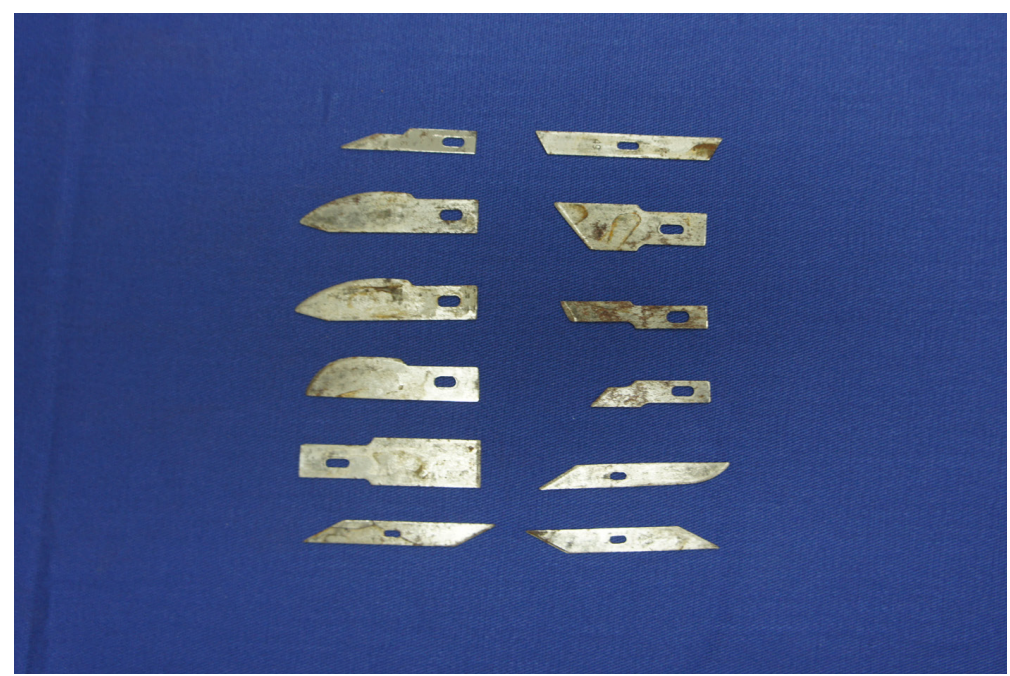

Figura 1. Lâminas que podem ser adaptadas no ferro de solda.

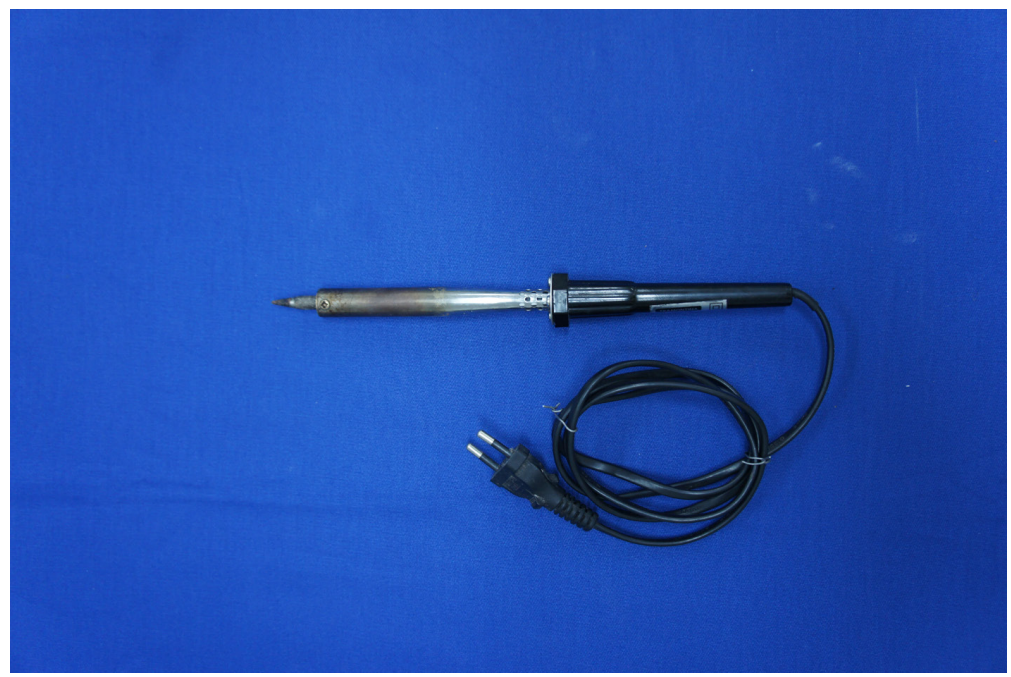

Figura 2. Ferro de solda utilizado na construção do modelo experimental.

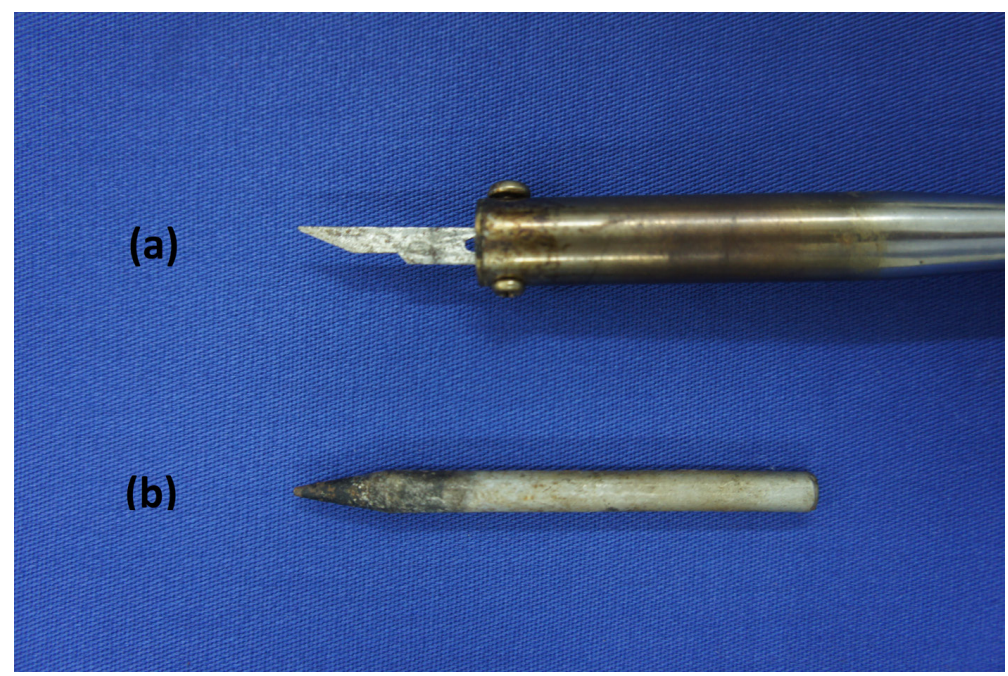

Figura 3. (a) Resultado final: Bisturi quente (ferro de solda adaptado) e sua (b) extremidade anterior à adaptação.

o cadáver não possui. Por fim, o modelo industrial possui uma pedagogia de estudo compartimentalizado: para estudar o corpo inteiro, é necessário adquirir várias peças de todas as partes do corpo, o que influencia diretamente no alto preço, característica que o cadáver não possui por ser um corpo completo. 
Logo, o estudo anatômico é mais vantajoso quando utilizado o cadáver humano, todavia, para o estudo, é necessário utilizar a técnica da dissecação. A dissecação é o estudo de explorar o corpo humano para diversas finalidades acadêmicas, sendo a principal delas: o estudo da Anatomia Humana. Esta técnica leva à construção do conhecimento biológico por ser desenvolvida em etapas tais como estudo e pesquisa da área a ser dissecada em livros texto e atlas de anatomia, desenvolvimento de habilidades manuais pela percepção instrumental cirúrgica (pinças anatômicas, tesouras, fios cirúrgicos e tesouras hemostáticas), aprendizado de possíveis variações anatômicas que podem refletir em diferenças fisiológicas, além da assimilação de noções de cautela e concentração em procedimentos frágeis que ajudarão na construção da graduação.

No entanto, a dissecação leva um tempo grande para encontrar seu objetivo por que a maioria das estruturas anatômicas são envoltas por tecido adiposo, o qual precisa ser retirado com cautela através do manuseio de instrumentais cirúrgicos para não lesar outras áreas.

Neste contexto, o modelo experimental de bisturi quente - ferro de solda adaptado - atende a necessidade da retirada do tecido adiposo com segurança para não lesionar outras áreas além de conseguir evidenciar áreas e estruturas, esculpir regiões em um tempo mais ágil e rápido para atender o objetivo pedagógico do aprendizado da Anatomia Humana.

Tal fato estimula o estudo do desenvolvimento de técnicas alternativas proporcionando melhor aprendizado em menor tempo e economizando dinheiro para o investimento em outras áreas na instituição de ensino.

\title{
Conclusão
}

O modelo experimental é uma alternativa segura na dissecação de tecido adiposo, sendo uma alternativa de baixo custo para a dissecação de estruturas anatômicas em cadáver, passível de construção e que viabiliza o estudo da Anatomia Humana de forma mais rápida e eficaz.

\section{Referências}

1. Os caminhos da educação médica. Rev Assoc Med Bras. 2004;50(3):229-30. http://dx.doi.org/10.1590/S0104-42302004000300001. PMid:15499456.

2. Fornaziero CC, Gordan PA, Carvalho MAV, Araujo JC, Aquino JCB. O ensino da anatomia: integração do corpo humano e meio ambiente. Rev Bras Educ Med. 2010;34(2):290-7. http://dx.doi.org/10.1590/S0100-55022010000200014.

3. Boechat JCS, Gama RV Fo, Sales EC, Silva MA, Manhães FC. Um estudo sobre abordagens didático-pedagógicas no ensino da anatomia humana. Revista Científica Internacional. 2016;11(1):42-55.

4. Costa GBF, Costa GBF, Lins CCSA. O cadáver no ensino da anatomia humana: uma visão metodológica e bioética. Rev Bras Educ Med. 2012;36(3):368-73.

5. Pontinha CM, Soeiro C. A dissecação como ferramenta pedagógica no ensino da Anatomia em Portugal. Interface (Botucatu). 2014;18(48):16576. http://dx.doi.org/10.1590/1807-57622014.0558.

\author{
Autor correspondente \\ Rafael de Azevedo Silva \\ Av. Visconde de Sousa Franco, 72, Reduto \\ CEP 66053-000, Belém, PA, Brasil \\ Tel.: (91) 98941-3817 \\ E-mail: azevedorafaelsilva@gmail.com
}

Informação sobre os autores

RAS, MSL, HDG são acadêmicos de Medicina da Faculdade Metropolitana da Amazônia (FAMAZ)

ESFM é fisioterapeuta pela Universidade da Amazônia (UNAMA) e especialista em Fisioterapia Intensiva (SUPOS - UNAMA)

MSRL é enfermeiro pela Universidade Federal do Pará (UFPA); mestre em Ciências Morfológicas pela Universidade Federal do Rio de Janeiro (UFRJ); docente do curso de Medicina da Faculdade Metropolitana da Amazônia (FAMAZ).

FCN é licenciado em Ciências Biológicas pela Universidade Vale do Acaraú (UVA - Ceará) e especialista em Entomologia Forense (Museu Emílio

Goeldi); docente do curso de Medicina da Faculdade Metropolitana da Amazônia (FAMAZ)

\section{Contribuição dos autores}

Rafael de Azevedo Silva e Marilia Silva da Luz contruíram o modelo experimental e fizeram a redação do artigo. Eduardo Silva Furtado de Mendonça e Hicaro Donato Granhen fizeram a redação do artigo. Franklin Coelho do Nascimento e Mauro Ricardo Souza da Luz auxiliaram com orientação do estudo anatômico e redação final.

Todos os autores leram e aprovaram a versão final submetida ao Pará Research Medical Journal. 